DOI: $10.20472 /$ IAC.2018.040.019

\author{
KALPAKAM GOPALAKRISHNAN \\ K J Somaiaya Institute of Management Studies and Research, India \\ SMITA RAMAKRISHNA \\ K J Somaiya Institute of Management Studies and Research, India
}

\title{
DO THE WINNERS REPEAT THEIR PERFORMANCE? A CASE INDIAN MUTUAL FUNDS?
}

\begin{abstract}
:
Mutual funds are vehicles for wealth generation in the long term. Therefore investors, fund managers and advisors need to predict the future winners in term of investment style and economic cycles. Indian mutual fund industry has reached new heights in the last decade and witnessed a healthy evolution in terms of number of players, number of folios opened and total assets under management. With a plethora of schemes available in the Indian market, investors before making any investment decision considers the past performance of these mutual fund schemes although past performance is not a guarantee for future performance. Thus, this paper analyses and presents the empirical evidence with regard to the performance persistence of mutual fund schemes and examines whether their past performance provides useful information for predicting the future performance. We have taken a sample of 30 mutual funds schemes and analysed for a period of eleven years from January 2007 to December 2017. For the analysis, various parametric and non-parametric techniques such as Risk Adjusted, regression analysis, etc have been used. Results are a mix of persistence and nonpersistence and do not confirm presence of performance persistence in mutual funds. The results are typical of an industry still evolving and in a nascent stage.
\end{abstract}

This study attempts to examine whether winners in terms of Risk Adjusted Returns and the Returns of a scheme are persisting/ repeating over a time span and also compare Midcap Mutual Funds with Largecap Mutual funds for performance persistence

Data is sourced from NAVIndia of Capitaline database for analysis. Monthly NAV of these equity schemes since 2007 is used. The sample would consist of thirty schemes from funds in India. For analysis, various parametric and non-parametric techniques such as Risk Adjusted, regression analysis, etc have been used

As long term investors, persistence in terms of returns and risk adjusted returns is an important factor to consider while investing in a fund. We find partial persistence over various time spans as well as in fund categories. This study helps investors and fund managers to base their decisions based on performance persistence.

\section{Keywords:}

Mutual Funds, Performance Evaluation, Performance Persistence 
JEL Classification: G11, N20 